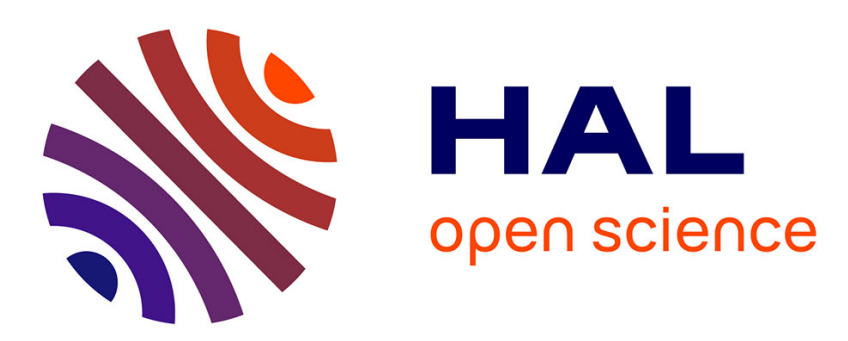

\title{
Sorption and desorption of organophosphate pesticides, parathion and cadusafos, on tropical agricultural soils
}

Angeluz Olvera-Velona, Pierre Benoit, Enrique Barriuso, Laura

Ortiz-Hernandez

\section{- To cite this version:}

Angeluz Olvera-Velona, Pierre Benoit, Enrique Barriuso, Laura Ortiz-Hernandez. Sorption and desorption of organophosphate pesticides, parathion and cadusafos, on tropical agricultural soils. Agronomy for Sustainable Development, 2008, 28 (2), pp.231-238. 10.105/agro:2008009 . hal-01191985

\section{HAL Id: hal-01191985 \\ https://hal.science/hal-01191985}

Submitted on 29 May 2020

HAL is a multi-disciplinary open access archive for the deposit and dissemination of scientific research documents, whether they are published or not. The documents may come from teaching and research institutions in France or abroad, or from public or private research centers.

$$
\text { Copyright }
$$

L'archive ouverte pluridisciplinaire HAL, est destinée au dépôt et à la diffusion de documents scientifiques de niveau recherche, publiés ou non, émanant des établissements d'enseignement et de recherche français ou étrangers, des laboratoires publics ou privés. 


\title{
Sorption and desorption of organophosphate pesticides, parathion and cadusafos, on tropical agricultural soils
}

\author{
Angeluz Olvera-VelonA ${ }^{1}$, Pierre BenOIT ${ }^{2 *}$, Enrique BARrIUSO ${ }^{2}$, Laura ORTIZ-HernANDEZ $^{1}$ \\ ${ }^{1}$ Centro de Investigación en Biotecnología, Universidad Autónoma del Estado de Morelos, 62210 Cuernavaca, Morelos, Mexico \\ 2 INRA-AgroParisTech., UMR Environnement et Grandes Cultures, 78850 Thiverval-Grignon, France
}

(Accepted 16 Junuary 2008)

\begin{abstract}
Ecotoxicological impacts of organic pesticides on soil and aquatic ecosystems depend primarily on their behavior in soils. Actual pesticide knowledge is mostly restricted to soils from temperate climates, whereas knowledge of pesticide behavior in tropical soils is scarce. Here, the sorption behavior of two organophosphorous insecticides, parathion and cadusafos, was studied in three agricultural soil samples from central Mexico, Vertisols and Andosols. Using ${ }^{14} \mathrm{C}$-labeled substances, we assessed sorption and desorption properties in classical batch equilibrium and static soil incubation experiments. Our results show that cadusafos was less sorbed by the various soils $\left(K_{\mathrm{d}}\right.$ values $\left.7.6-12.7 \mathrm{Lkg}^{-1}\right)$ compared with parathion ( $K_{\mathrm{d}}$ values 38.6-74.9 $\mathrm{L} \mathrm{kg}^{-1}$ ), despite similar $\log K_{\mathrm{ow}}$ values. Cadusafos exhibited a greater reversibility of sorption than parathion in both soil types. Time-dependent sorption was quantitatively significant, leading to a rapid decrease in the concentration of available insecticide. This finding is partly due to the formation of non-extractable, bound residues. The decrease in the available concentration of both insecticides was greater in the Andosol compared with the Vertisols. Soil organic matter clearly influenced the sorption behavior and availability of parathion. On the other hand, the sorption of cadusafos was more influenced by other soil properties such as clay content and cation exchange capacity. Calculation of residual insecticide levels in the soil solution suggests that both insecticides may have persistent toxic effects in the studied soils.
\end{abstract}

desorption / organophosphorous / insecticides / adsorption

\section{INTRODUCTION}

In Mexico, the agricultural use of pesticides has been generalized to many states and has considerably increased in the last few decades due to the development of intensive food production in some parts of the country (INEGI, 2004). Morelos State, with a large variety of crops cultivated in relatively intensive cropping systems ( 3 to 4 crop cycles per year), is representative of the agriculture of central Mexico. In this area, organophosphorous pesticides are still the main category of insecticides used (INEGI, 2004). Regarding the toxicity of these compounds and their degradation products, their widespread use has been reconsidered in several countries through limitations and interdictions. However, the persistent use of certain organophosphorous compounds necessitates evaluation of the risks to groundwater from movement through the soils and to soil organisms from uptake and transfer through the food chain (Pehkonen and Zhang, 2002). This is particularly needed in southern countries where available data on the effects of climatic and soil factors are less documented (Racket, 2003).

* Corresponding author: benoit@grignon.inra.fr
Among the organophosphate compounds largely used, cadusafos [S,S-di-sec-butyl $O$-ethyl phosphorodithioate] is a nematicide and insecticide against a broad spectrum of nematodes and soil insects. It is employed on several important crops of Mexico, and other countries of central America, such as banana, tomato, sugar cane coffee, citrus, maize and agave. This compound has a high toxicity and is also relatively mobile in the environment (Zheng et al., 1994; Agritox, 2005). Parathion [O,O-diethyl $O$-(4-nitrophenyl) phosphorothioate] is an insecticide formerly used on several crops. Due to its toxicity, its use has been restricted since 1991, but methylparathion is still used in Mexico (CICLOPLAFEST, 2004).

The behavior of pesticides in soils strongly depends on adsorption-desorption phenomena. As these processes influence the composition of the soil solution, knowledge and understanding of them is important to accurately predict the mobility and the bioavailability of these chemicals in soils, and therefore to limit their impact on non-targeted organisms and ecosystems. Pesticide availability in soil can be evaluated using indirect and direct methods. The most common indirect method to characterize pesticide availability is by using a 
simplistic partition coefficient $\left(K_{\mathrm{d}}\right)$. Many pesticide fate models have traditionally used sorption $K_{\mathrm{d}}$ values to predict the amount of pesticide that can be available in solution at a given time. However, sorption-desorption processes are complex and cannot be described by a single value assuming instantaneous totally reversible sorption (Koskinen and Harper, 1990; Pignatello, 2000).

Desorption processes control the release rates of pesticide into the soil solution and therefore have a major control of availability and bioavailability to soil organisms (Weber et al., 1993). Non-reversible sorption and hysteresis effects concern many pesticides (Koskinen and Harper, 1990; Pignatello, 2000). This implies that desorption cannot be predicted from their sorption isotherms. Increasing pesticide contact time or ageing affects sorption and desorption processes, and generally desorption decreases with the residence time in soil (Pignatello, 2000; Mamy and Barriuso, 2007). As a consequence, the availability of pesticide for transport or uptake by soil organisms decreases with time (Führemann et al., 1978; Weber et al., 1993; Gevao et al., 2001).

Several pedological factors are known to regulate sorption and desorption processes (Barriuso and Calvet, 1991; Weber et al., 2004). For ionized molecules, mineralogical composition and soil $\mathrm{pH}$ are key parameters, whereas sorption of neutral compounds is mostly governed by the soil organic matter (Hamaker and Thompson, 1972; Wauchope et al., 2002). These generally accepted rules have been obtained in studies considering large numbers of soil types and origins. Nevertheless, the role of soil characteristics is less documented for tropical soils compared with temperate soils (Barriuso et al., 1992; Zheng and Cooper, 1996; Oliver et al., 2005; Laabs and Amelung, 2005). Comparing the sorption properties of herbicides on various soil types including tropical soils such as Andosols, Vertisols and Ferralsols, Barriuso and Calvet (1991) have shown that relations between sorption and soil type characteristics strongly depend on molecular properties such as electrical state and polarity. The combination of the effects of soil organic matter and of mineral constituants such as smectite-type clays (Vertisols) and amorphous claysallophanes (Andosols) usually increases the sorption of neutral molecules (Barriuso and Calvet, 1991).

The present study aimed to identify the main soil parameters affecting the sorption and desorption of cadusafos and parathion on agriculturally-representative tropical soils (Vertisols and Andosols from central Mexico). The relationships between the experimental parameters, soil properties and physico-chemical characteristics of the two compounds were examined to predict the availability of the pesticides. Laboratory incubations were also carried out to study the influence of time on the retention of the insecticides and to evaluate the availability of their residues.

\section{MATERIALS AND METHODS}

\subsection{Soil samples}

The soils originated from Morelos state, Mexico. They were selected on the basis of their relative extension on the regional
Table I. Physico-chemical characteristics and texture of the soils (0$20 \mathrm{~cm}$ layer). Soil analyses were performed by the soil analysis laboratory (INRA Arras) according to ISO reference methods (AFNOR, 2005).

\begin{tabular}{|c|c|c|c|}
\hline Parcel location & Ayala & Yautepec & Huitzilac \\
\hline Soil & Vertisol 1 & Vertisol 2 & Andosol \\
\hline $\mathrm{pH}_{\text {water }}$ & 8.0 & 7.1 & 5.6 \\
\hline Sand $\mathrm{g} / \mathrm{kg}$ & 494 & 418 & 550 \\
\hline Silt g/kg & 108 & 224 & 272 \\
\hline Clay $\mathrm{g} / \mathrm{kg}$ & 398 & 358 & 178 \\
\hline Organic carbon $\mathrm{g} / \mathrm{kg}$ & 10.8 & 17.8 & 54.3 \\
\hline Total N g/kg & 0.804 & 1.44 & 3.67 \\
\hline $\mathrm{C} / \mathrm{N}$ & 13.5 & 12.4 & 14.8 \\
\hline C.E.C $\mathrm{cmol}_{\mathrm{c}} / \mathrm{kg}$ & 44.6 & 23.9 & 21.9 \\
\hline $\mathrm{Ca}^{2+}$ exch. $\mathrm{cmol}_{\mathrm{c}} / \mathrm{kg}$ & 29.5 & 14.3 & 4.96 \\
\hline $\mathrm{Mg}^{2+}$ exch. $\mathrm{cmol}_{\mathrm{c}} / \mathrm{kg}$ & 16.4 & 7.38 & 0.464 \\
\hline $\mathrm{K}^{+}$exch. $\mathrm{cmol}_{\mathrm{c}} / \mathrm{kg}$ & 0.404 & 1.57 & 0.447 \\
\hline $\mathrm{Na}^{+}$exch. $\mathrm{cmol}_{\mathrm{c}} / \mathrm{kg}$ & 1.93 & 0.108 & 0.050 \\
\hline $\mathrm{Al}^{3+}$ exch. $\mathrm{cmol}_{\mathrm{c}} / \mathrm{kg}$ & $<0.05$ & $<0.05$ & 0.279 \\
\hline $\mathrm{Al}$ - total $\mathrm{g} / \mathrm{kg}$ & 8.39 & 9.16 & 8.84 \\
\hline $\mathrm{Al}$ - Tamm g/kg & 0.177 & 0.134 & 3.03 \\
\hline $\mathrm{Fe}-$ total $\mathrm{g} / \mathrm{kg}$ & 3.51 & 3.4 & 4.47 \\
\hline $\mathrm{Fe}-\mathrm{Tamm} \mathrm{g} / \mathrm{kg}$ & 0.061 & 0.127 & 1,09 \\
\hline $\mathrm{P}$ - total $\mathrm{g} / \mathrm{kg}$ & 0.028 & 0.0548 & 0.0229 \\
\hline $\mathrm{P}-$ Olsen $\mathrm{g} / \mathrm{kg}$ & 0.013 & 0.0540 & 0.0010 \\
\hline
\end{tabular}

scale, their texture and organic matter content (Tab. I). According to the FAO soil classification (WRB, 1998), soil types were classified as Andosol (Huitzilac site) and Vertisol (Ayala and Yautepec sites). In Morelos state, Andosols represent 12\% of the land and are located in the northern temperate region of the state. Developed on slopes of the volcanic sierras, these soils naturally covered by forests have recently been converted for agriculture (INEGI, 2004).

Vertisols represent $21 \%$ of the total surface and are mainly distributed in the temperate subtropical area in the south of Morelos state. Historically, these soils have been used for agriculture for a very long period due to their fertility (INEGI, 2004).

Soils were taken from the surface layers $(0-20 \mathrm{~cm})$ of cultivated plots. A composite sample was formed from 5 samples randomly taken in each plot. The samples were air-dried and sieved at $2 \mathrm{~mm}$. Soil properties are summarized in Table I. The Andosol was acid, whereas the Vertisols were neutral (Vertisol 2) to moderately basic (Vertisol 1). According to texture, soils were classified as sandy loam (Andosol), sandy clay (Vertisol 1) and clay loam (Vertisol 2). The soil organic carbon content was much greater in the Andosol compared with the Vertisols. Between the two Vertisols, the soil organic content differed significantly (Tab. I). 
Table II. Selected physico-chemical properties of cadusafos and parathion (data from FOOTPRINT, 2006).

\begin{tabular}{|c|c|c|c|c|c|c|c|}
\hline Insecticide & Molecular formula & $\begin{array}{c}\mathrm{m} . \mathrm{w} . \\
\mathrm{g} \mathrm{mol}^{-1}\end{array}$ & $\begin{array}{c}\text { Solubility in water } \\
\mathrm{mg} \mathrm{L}^{-1}, 20^{\circ} \mathrm{C}\end{array}$ & $\log K_{\text {ow }}$ & $\begin{array}{c}\text { Vapor Pressure } \\
\mathrm{mPa}, 25^{\circ} \mathrm{C} \\
\end{array}$ & $\begin{array}{c}K_{\mathrm{oc}} \\
\mathrm{L} \mathrm{kg}^{-1} \\
\end{array}$ & $\begin{array}{c}\text { DT } \\
50 \text { days }\end{array}$ \\
\hline Cadusafos & 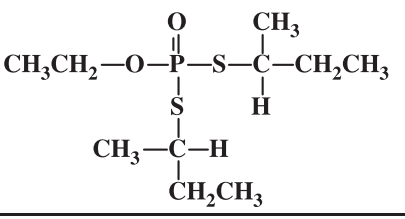 & 270.4 & 245 & 3.85 & 119.6 & 227 & 38 \\
\hline Parathion & $\begin{array}{c}\mathrm{H}_{5} \mathrm{C}_{2}-\mathrm{O}-\stackrel{\|}{\mathrm{P}}-\mathrm{O}-\mathrm{I} \\
\mathrm{O} \\
1 \\
\mathrm{C}_{2} \mathrm{H}_{5}\end{array}$ & 291.3 & 12.4 & 3.83 & 0.89 & 7660 & 49 \\
\hline
\end{tabular}

\subsection{Insecticides}

${ }^{14} \mathrm{C}-\mathrm{U}$-labeled parathion (specific activity $933 \mathrm{MBq}$ $\mathrm{mmol}^{-1}$; radiopurity $\left.95 \%\right)$ and 2 -mercapto 1 - $\left({ }^{14} \mathrm{C}\right)$-cadusafos (specific activity $833 \mathrm{MBq} \mathrm{mmol}^{-1}$; radiopurity $98 \%$ ) were purchased from the Institute of Isotopes Co., Ltd. (H-1121 Budapest). Selected molecular characteristics of both insecticides are reported in Table II. Aqueous solutions of ${ }^{14} \mathrm{C}$ parathion and ${ }^{14} \mathrm{C}$ cadusafos were prepared in $0.01 \mathrm{M} \mathrm{CaCl}_{2}$ for the sorption and incubation experiments.

\subsection{Sorption/desorption experiments}

Sorption isotherms were carried out with the batch equilibrium method using glass centrifuge tubes closed with Teflon caps. Triplicate soil aliquots ( $5 \mathrm{~g}$ of air-dried, $<2-\mathrm{mm}$ sieved soil) were equilibrated with $10 \mathrm{~mL}{ }^{14} \mathrm{C}$-labeled parathion or cadusafos aqueous solution by gently rotating in an end-overend shaker at $20 \pm 2{ }^{\circ} \mathrm{C}$ for 24 hours. A preliminary kinetic experiment showed that apparent equilibrium was reached within 24 hours for parathion and cadusafos. Intitial concentrations were $0.01,0.04,0.08$ and $0.36 \mathrm{mg} \mathrm{L}^{-1}$ for parathion and $0.04,0.09,0.16,0.30$ and $0.56 \mathrm{mg} \mathrm{L}^{-1}$ for cadusafos. The ${ }^{14} \mathrm{C}$ activity of the initial solutions ranged between 60 and $3200 \mathrm{kBq} \mathrm{L}^{-1}$. After equilibration, the soil suspensions were centrifuged for $15 \mathrm{~min}$ at $1800 \mathrm{~g}$ (centrifuge Sorvall Evolution RC). The radioactivity in the supernatant was measured and allowed to determine the pesticide concentration in solution after equilibration, $C_{\mathrm{e}}\left(\mathrm{mg} \mathrm{L}^{-1}\right)$. The amount of pesticide sorbed on the soils, $x / m$ ( $\mathrm{mg} \mathrm{kg}^{-1}$ soil), was calculated from the concentration difference between the initial pesticide solution, $C_{\mathrm{o}}$, and $C_{\mathrm{e}}: x / m=\left[\left(C_{0}-C_{\mathrm{e}}\right) V\right] / m$; where $V$ is the volume of solution and $m$ is the mass of soil.

Sorption isotherms were described with the Freundlich equation $x / m=K_{\mathrm{fa}} C_{\mathrm{e}}^{n a}$ where $K_{\mathrm{fa}}$ and $n_{\mathrm{a}}$ are empirical parameters related to the the capacity and intensity of sorption, respectively. Freundlich parameters were used to estimate $K_{\mathrm{d}}$ parameters by recalculating $x / m$ at one fixed concentration in solution $\left(0.02 \mathrm{mg} \mathrm{L}^{-1}\right) . K_{\mathrm{d}}$ was estimated as follows:

$$
K_{\mathrm{d}}=x / m / C_{\mathrm{e}}
$$

From $K_{\mathrm{d}}$ values, we calculated $K_{\mathrm{oc}}$ coefficients using the organic carbon content of each soil:

$$
K_{\mathrm{oc}}=K_{\mathrm{d}} \times 100 / \text { soil organic content in \% }
$$

Samples spiked with the highest initial concentrations in the adsorption experiment $\left(0.36 \mathrm{mg} \mathrm{L}^{-1}\right.$ for parathion and $0.56 \mathrm{mg} \mathrm{L}^{-1}$ for cadusafos) were used for the desorption study. Desorption was measured after replacing the supernatant with $10 \mathrm{~mL}$ of fresh $0.01 \mathrm{M} \mathrm{CaCl}_{2}$ and shaking the soil suspensions for $24 \mathrm{~h}$. Then the suspensions were centrifuged and the pesticide concentration determined in the supernatant as described above; this allowed calculation of the desorbed amount. This desorption procedure was repeated until the radioactivity in the supernatant was negligible. This led to five successive desorptions for parathion and eight desorptions for cadusafos. Desorption isotherms were described using the Freundlich equation:

$$
x / m=K_{\mathrm{fd}} C^{n d}
$$

where $K_{\mathrm{fd}}$ and $n_{\mathrm{d}}$ are parameters related to the capacity to desorb and to the intensity of desorption, respectively. We used the hysteresis index, $\mathrm{H}$, defined as the ratio $n_{\mathrm{d}} / n_{\mathrm{a}}$ (Barriuso et al., 1994), where $n_{\mathrm{a}}$ and $n_{\mathrm{d}}$ are the exponents of Freundlich equations for the adsorption and desorption isotherms, respectively. All Freundlich parameters were estimated by non-linear regression using the Marquardt-Levenberg algorithm inserted in the SigmaPlot software (Jandel Corporation). In practice, hysteresis is observed when $\mathrm{H}<0.7$. When $\mathrm{H}$ decreases, the hysteresis increases, indicating a more irreversible sorption.

\subsection{Time-dependent availability and apparent sorption coefficients}

Fresh soil samples of Andosol or Vertisol 2 (30 g of dry soil equivalent) were incubated under aerobic conditions in the dark at $15 \pm 1{ }^{\circ} \mathrm{C}$ in sealed $1000-\mathrm{mL}$ jars with a vial containing $\mathrm{NaOH}(2 \mathrm{M}, 10 \mathrm{~mL})$ to trap the $\mathrm{CO}_{2}$ evolved. Soil water content was adjusted to the water-holding capacity, estimated at $\mathrm{pF}=2.8$, by adding aqueous insecticide solution and MilliQ water (Millipore). Water content of treated samples was $20 \%(\mathrm{w} / \mathrm{w})$ for the Vertisol and $50 \%(\mathrm{w} / \mathrm{w})$ for the Andosol. The final concentrations of ${ }^{14} \mathrm{C}$ insecticide applied 
were $0.15 \mathrm{mg} \mathrm{kg}^{-1}$ dry soil for cadusafos and $0.9 \mathrm{mg} \mathrm{kg}^{-1}$ dry soil for parathion, and corresponded to the recommended agronomical dose. The dose of cadusafos was calculated on the basis of its use in banana crops ( $30 \mathrm{~g}$ of Rugby ${ }^{\circledR} 10 \mathrm{G}$ per plant applied to a radius of $30 \mathrm{~cm}$ ). The applied radioactivity was $0.69 \mathrm{MBq} \mathrm{kg}{ }^{-1}$ and $0.37 \mathrm{MBq} \mathrm{kg}^{-1}$ dry soil for cadusafos and parathion, respectively. The $\mathrm{NaOH}$ traps were periodically sampled and replaced. The incubations were set up in triplicate.

At $0,4,11$ and 32 days after the beginning of the incubation, insecticide residues were extracted sequentially. Each soil sample in its totality was successively extracted by $60 \mathrm{~mL}$ of aqueous $0.01 \mathrm{M} \mathrm{CaCl}_{2}$ and then three times with $60 \mathrm{~mL}$ of methanol in Pyrex glass centrifuge tubes. Each extraction lasted $24 \mathrm{~h}$ with end-over-end shaking at room temperature. Extracts were recovered by centrifugation $(15 \mathrm{~min}$ at $1800 \mathrm{~g})$ and ${ }^{14} \mathrm{C}$ activity content was measured. After extraction, soil samples containing non-extractable ${ }^{14} \mathrm{C}$ insecticide residues were air-dried and kept until analysis.

The procedure for extraction of water-soluble ${ }^{14} \mathrm{C}$ residues was similar to that used to measure sorption and desorption by the batch technique with comparable soil:solvent ratios, equilibration procedure and supernatant recovery. The concentration of insecticide residue in the water extract was used to calculate an apparent sorption coefficient, $K_{\mathrm{d} \text { app }}\left(\mathrm{L} \mathrm{kg}^{-1}\right)$, for each insecticide during the incubation period. $K_{\mathrm{d}}$ app values were estimated by considering the insecticide concentrations in the $\mathrm{CaCl}_{2}$ extract. The amounts of sorbed insecticide were estimated as the total insecticide residues remaining in the soil, calculated as the sum of methanol-extracted residues plus non-extractable residues. All calculations were done using the insecticide concentration from the HPLC analysis of the extracts (HPLC: high-performance liquid chromatography). The proportions of non-degraded insecticide in non-extractable residues were assumed to be equal to the proportion found in the methanol extracts (Mamy and Barriuso, 2007).

\subsection{Analysis}

Total radioactivity content was measured by liquid scintillation counting using a Packard Tri-Carb 2100TR (Packard, Meriden, CT, USA) counter with external standardization and Ultima Gold XR (Packard) as a liquid scintillation cocktail. Amounts of ${ }^{14} \mathrm{C}$ insecticide present in water (batch sorption desorption and extraction) and methanol extracts were determined on $0.5-\mathrm{mL}$ aliquots using $4 \mathrm{~mL}$ of liquid scintillation cocktail. For the incubation experiment, the radioactivity in $\mathrm{NaOH}$ traps was measured on $1-\mathrm{mL}$ aliquots mixed with $10 \mathrm{~mL}$ of liquid scintillation cocktail.

Replicate extracts containing sufficient radioactivity were pooled and kept for HPLC analysis. Water extracts were concentrated by solid phase extraction with an Env+ cartridge (200 mg; Isolute, Glamorgan, UK), previously activated with methanol and MilliQ water and eluted with $5 \mathrm{~mL}$ methanol. Finally, $2 \mathrm{~mL}$ of water was added to adjust solvent composition for the HPLC analysis. Methanol extracts were concentrated by evaporation close to dryness under vacuum at $45^{\circ} \mathrm{C}$.
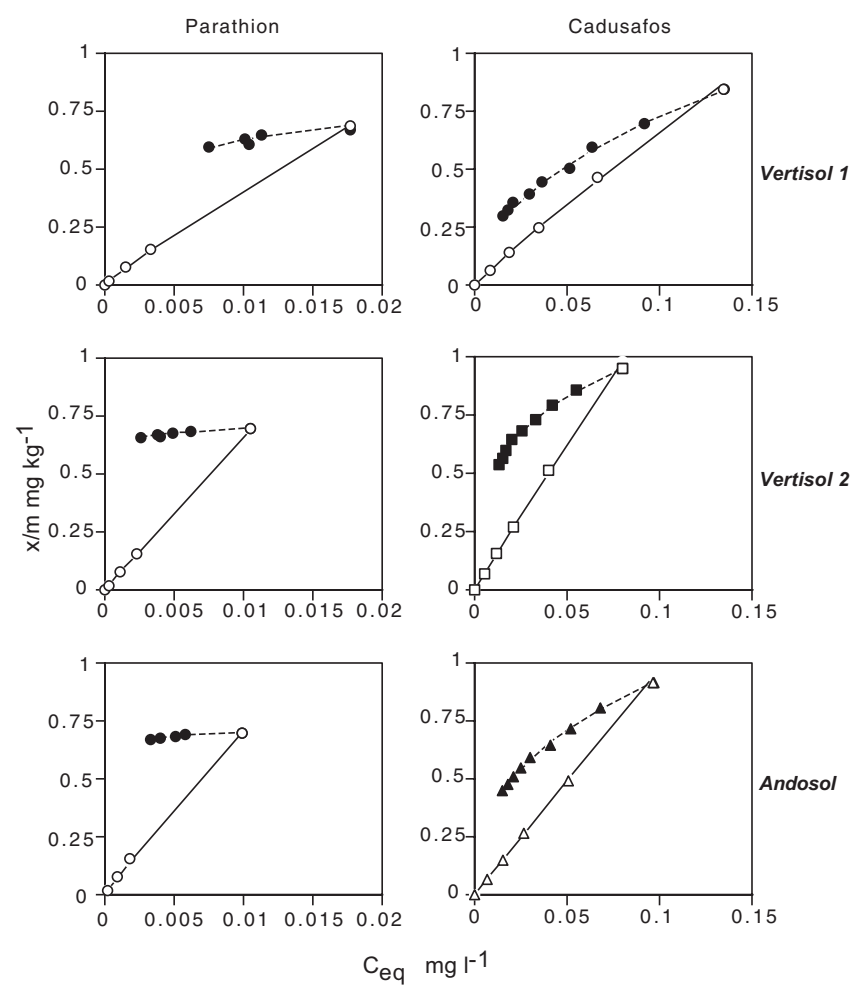

Figure 1. Sorption (empty symbols) and desorption (plain symbols) isotherms of parathion and cadusafos on the three soils. Plain and dotted lines correspond to the fitting using the Freundlich equation.

Residues were then dissolved in 50/50 methanol-water (v/v) filtered through regenerated cellulose disc filters $(0.45 \mu \mathrm{m}$; Alltech, Strasbourg, France). All samples were analyzed using a Waters HPLC appliance (600E Multisolvent Delivery System, 717 Autosampler and a Novapack column of $5 \mu \mathrm{m}$ and $4.6 \times 250 \mathrm{~mm}$; Waters, Milford, MA, USA) equipped with a PhotoDiode Array detector (Waters 990) and a radioactive flow detector (Packard-Radioamatic Flo-One A550). The mobile phase was 50/50 methanol-water. The injected sample volume was $200 \mu \mathrm{L}$ and the mobile phase flow was $1.0 \mathrm{~mL} \mathrm{~min}^{-1}$. Parathion, paraoxon and para-nitrophenol were analyzed (retention times equal to 36,6 and $7 \mathrm{~min}$., respectively). Only cadusafos was available as ${ }^{14} \mathrm{C}$ standard and could be identified (retention time equal to $28 \mathrm{~min}$.)

The non-extractable radioactivity, corresponding to nonextractable residues, was measured by LSC after combustion of the extracted soil samples using a Packard B307 Sample Oxidizer and trapping the ${ }^{14} \mathrm{CO}_{2}$ released with CarboSorb, using Permafluor (Packard) as a scintillation cocktail.

\section{RESULTS AND DISCUSSION}

\subsection{Cadusafos and parathion sorption}

Sorption was studied for the three different soils and characterized through sorption isotherms (Fig. 1). Sorption isotherms 
Table III. Freundlich sorption coefficients $\left(K_{\mathrm{f} \text { ads }}, n_{\mathrm{ads}}\right)$ and partition coefficients $K_{\mathrm{d}}$ and $K_{\mathrm{oc}}$ calculated for a solution concentration at equilibrium of $0.02 \mathrm{mg} \mathrm{L}^{-1}$. Values are means \pm standard errors.

\begin{tabular}{|c|c|c|c|c|c|}
\hline & $K_{\mathrm{f} \text { ads }}$ & $n_{\text {ads }}$ & $R^{2}$ & $K_{\mathrm{d}}\left(\mathrm{L} \mathrm{kg}^{-1}\right)$ & $K_{\mathrm{oc}}\left(\mathrm{L} \mathrm{kg}^{-1}\right)$ \\
\hline \multicolumn{6}{|l|}{ Parathion } \\
\hline Vertisol 2 & $49.2 \pm 7.0$ & $0.952 \pm 0.053$ & 0.99 & $68.6 \pm 5.4$ & $4514 \pm 353$ \\
\hline \multicolumn{6}{|l|}{ Cadusafos } \\
\hline Vertisol 1 & $5.7 \pm 0.2$ & $0.938 \pm 0.012$ & 0.99 & $7.3 \pm 0.1$ & $943 \pm 9$ \\
\hline Vertisol 2 & $11.6 \pm 0.4$ & $0.977 \pm 0.007$ & 0.99 & $12.7 \pm 0.1$ & $835 \pm 5$ \\
\hline
\end{tabular}

were well described by the Freundlich equation with regression coefficients $\mathrm{R}^{2}>0.99$; sorption parameters $\left(K_{\mathrm{f}}\right.$ and $n_{\mathrm{a}}$ ) are given in Table III. The empirical parameter, $n_{\mathrm{a}}$, indicates the intensity of the adsorption process and traduces the affinity of the molecules for the different soil sorbents. All isotherms were almost linear, with $n_{\mathrm{a}}>0.9$ (Tab. III). The pseudo-linearity of sorption isotherms in the range of concentrations studied justified the calculation of $K_{\mathrm{d}}$ and $K_{\mathrm{oc}}$ at a single concentration in order to compare the sorption capacities of the different soils (Tab. III). $K_{\mathrm{d}}$ values ranged from 7.3 to 12.7 $\mathrm{L} \mathrm{kg}^{-1}$ for cadusafos and from 38.6 to $74.9 \mathrm{~L} \mathrm{~kg}^{-1}$ for parathion. Parathion was sorbed by all soils to a greater extent than cadusafos, and this was related to its lower solubility in water, as already observed for many non-ionized organic contaminants (Hassett et al., 1983).

We observed a greater sorption of parathion in the Andosol compared with the two Vertisols, and it was the lowest in the less organic Vertisol (Vertisol 1). These results are in agreement with previous studies showing the predominant role of soil organic matter in parathion sorption (Saltzmann et al., 1972; Sanchez Martin and Sanchez Camazano, 1991). The case of cadusafos was different, since sorption decreased in the order Vertisol $2>$ Andosol $>$ Vertisol 1. Despite a much higher soil organic carbon content, Andosol sorbed less cadusafos than Vertisol 2.

Normalization of parathion and cadusafos $K_{\mathrm{d}}$ to the organic $\mathrm{C}$ content of the soils reduced the variability between the two Vertisols (Tab. III). However, the variability between Vertisol and Andosol was increased. $K_{\mathrm{oc}}$ of both compounds were significantly lower for the Andosol compared with the Vertisols, suggesting that parathion and cadusafos had a stronger affinity for the organic matter of the second soil type. The soil organic matter quality present in both soil types could influence sorption directly due to differences in chemical composition (Allen-King et al., 2002). This supports the idea that the amount of $\mathrm{C}$ alone cannot explain the different sorptive properties of soils (Worrall et al., 1996; Allen-King et al., 2002). In the different soil types, other factors such as the nature of major cations bound to soil organic matter (Leenheer and Ahlrichs, 1971), the interactions between organic matter and mineral constituents (Kaiser and Guggenberger, 2003) or soil pH (Barriuso and Calvet, 1991) can influence pesticide sorption. Regarding $\mathrm{pH}$ influence, sorption of non-ionic hydrophobic compounds generally increases when the majority of sorption sites located on soil organic matter or mineral ox- ides become uncharged and neutral due to proton exchange reactions (Calvet et al., 2005).

We found higher $K_{\mathrm{oc}}$ values in the Vertisol 1, where the amount of organic carbon was the lowest. As already observed in temperate soils, the participation of mineral fractions, mainly clay minerals, in pesticide sorption was suspected to increase when the soil organic matter content decreases (Worall et al., 1996). Several studies, mainly conducted in temperate soils with organic content ranging around $10 \mathrm{~g} \mathrm{~kg}^{-1}$, have shown that parathion sorption was influenced by the clay content and cation exchange capacities of soils (Yaron and Saltzmann, 1978). Sanchez Martin and Sanchez Camazano (1991) showed that the sorption of thiophosphate pesticides, such as parathion and methyl-parathion, was mainly controlled by soil organic matter, whereas sorption of the degradation products paraoxon and methyl paraoxon was more related to the clay content or the clay-organic matter association. In different tropical soil types from Martinique, all with relatively low soil organic carbon content (11 to $26 \mathrm{~g} \mathrm{~kg}^{-1}$ ) compared with our soils, Zheng and Cooper (1996) found that the cationic exchange capacity and the clay content were explicative factors of the sorption of cadusafos. On the contrary, sorption of cadusafos was not correlated with the soil organic matter content (Zheng and Cooper, 1996). In the present study, $K_{\mathrm{oc}}$ values obtained for cadusafos were in the superior range of values published for Vertisols by Zheng and Cooper (1996), $\left(K_{\mathrm{oc}}=419\right.$ to $\left.621 \mathrm{~L} \mathrm{~kg}^{-1}\right)$ and similar to the values found for Andosols. Despite too small a number of soils, our results suggest that soil organic matter had a less important role in the sorption of cadusafos compared with parathion. Our results therefore confirmed the role of molecular structure and the presence of thiophosphate or phosphate groups in sorption processes.

\subsection{Cadusafos and parathion desorption}

Desorption isotherms were hysteretic for both cadusafos and parathion (Fig. 1) and fitted well to the Freundlich equation with regression coefficients greater than 0.9, except for the desorption isotherm of parathion on Vertisol 1 (Tab. IV). Hysteresis was systematically greater for parathion than for cadusafos (Tab. IV). For both molecules, the lower values of the hysteresis index, H, were observed in the Andosol and Vertisol 2, suggesting that sorption irreversibility was higher in 
Table IV. Freundlich desorption coefficients $\left(K_{\mathrm{f} \text { des }}, n_{\mathrm{ads}}\right)$, hysteresis index, H, calculated as the ratio $n_{\mathrm{des}} / n_{\mathrm{ads}}$ and proportion of desorbed pesticide (\% of initially sorbed). Values are means \pm standard errors.

\begin{tabular}{lccccc}
\hline & $K_{\mathrm{f} \text { des }}$ & $n_{\text {des }}$ & $r^{2}$ & $H$ & Desorbed proportion \% \\
\hline Paration & & & & & \\
Vertisol 1 & $1.42 \pm 0.04$ & $0.178 \pm 0.005$ & 0.80 & $0.19 \pm 0.00$ & $13.4 \pm 0.8$ \\
Vertisol 2 & $0.84 \pm 0.01$ & $0.041 \pm 0.003$ & 0.91 & $0.04 \pm 0.00$ & $5.2 \pm 0.8$ \\
Andosol & $0.85 \pm 0.01$ & $0.041 \pm 0.002$ & 0.96 & $0.04 \pm 0.00$ & $4.4 \pm 0.6$ \\
Cadusafos & & & & \\
Vertisol 1 & $2.30 \pm 0.06$ & $0.501 \pm 0.005$ & 0.99 & $0.53 \pm 0.01$ & $65.4 \pm 0.4$ \\
Vertisol 2 & $1.99 \pm 0.01$ & $0.292 \pm 0.004$ & 0.99 & $0.30 \pm 0.01$ & $41.2 \pm 0.9$ \\
Andosol & $2.30 \pm 0.06$ & $0.392 \pm 0.009$ & 0.99 & $0.39 \pm 0.01$ & $51.5 \pm 0.5$ \\
\hline
\end{tabular}

these two soils compared with the Vertisol 1. The amounts of desorbed parathion after five desorptions, expressed as a percentage of initial sorbed amount, varied between 4 (Andosol) and 13\% (Vertisol 1). For cadusafos, these proportions exceeded $40 \%$ in all soils. For both pesticides, a greater hysteresis was observed for the soil with the greatest sorption capacity.

For the less water-soluble parathion, we found a more difficult desorption from the more organic soil. Effects of the mineral fractions (clays, oxy-hydroxides and the nature of cations) have been reported by Bowman and Sans (1977), who observed a greater hysteresis with $\mathrm{Fe}^{3+}$-montmorillonite than with $\mathrm{Ca}^{2+}$-montmorillonite. In the two Vertisols studied, clays are mainly saturated by $\mathrm{Ca}^{2+}$ (Tab. I). Due to the high content of organic matter and very different types of organomineral association in the Andosol, the role of amorpheous Al mineral constituents was difficult to isolate.

The greater desorption of cadusafos was related to its higher solubility in water (Weber et al., 1993; Zheng and Cooper, 1996). Despite a greater desorption in the less organic Vertisol (Vertisol 1), our results obtained for cadusafos suggest that soil organic matter probably had a less important role in the control of desorption than for parathion. In soils from Martinique, Zheng and Cooper (1996) showed that desorption of cadusafos was lower in Vertisols (desorbed amounts 55-61\%) than in an Andosol (desorbed amount $77 \%$ ). In these soils, with less organic carbon than $26 \mathrm{mg} \mathrm{kg}^{-1}$, these authors showed significant correlation between desorbed quantities and clay content.

\subsection{Availability of insecticide residues in soil and time- dependent sorption}

Insecticide degradation products were recovered in the aqueous and mostly in the methanol extracts during the incubation, suggesting that metabolites were released into the soil solution. In the case of parathion, the major metabolite identified was p-nitophenol. Paraoxon was only detected in the first days of incubation and then disappeared. As previously noticed in other soils, paraoxon probably has a transient presence in soil and is rapidly degraded into p-nitrophenol and other metabolites (Saffih-Hdaddi et al., 2003). In total, degradation products of parathion did not represent more than $6 \%$ of extracted radioactivity at the end of the incubation. For
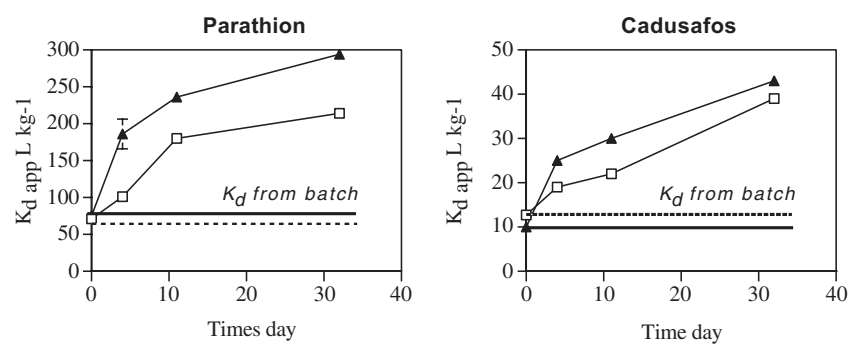

Figure 2. Variation with time of the apparent sorption coefficient $K_{\mathrm{d}}$ app of parathion and cadusafos measured during incubation in the Vertisol 2 ( $\square$ ) and the Andosol ( $\mathbf{\Delta}$ ). Values of $K_{\mathrm{d}}$ obtained at $24 \mathrm{~h}$ equilibrium in batch suspension are represented by the horizontal lines (plain line for Andosol and dotted line for Vertisol).

cadusafos, an unidentified metabolite was detected and represented between 1 and $6 \%$ of extracted radioactivity after $32 \mathrm{~d}$. These results suggest a relatively slow degradation, also confirmed by the low mineralization rate. Indeed, less than $10 \%$ of initial cadusafos was evolved as ${ }^{14} \mathrm{C}-\mathrm{CO}_{2}$ at the end of incubation (data not shown).

We took into account the decrease in insecticide concentration in water with the incubation time in the calculation of the apparent sorption coefficient, $K_{\mathrm{d}}$ app, (Fig. 2). Initial values of $K_{\mathrm{d}}$ app were in the same range as the $K_{\mathrm{d}}$ obtained from the batch sorption isotherms in the case of the Vertisol 2 (horizontal lines in Fig. 2). For the Andosol, apparent sorption coefficients were almost two times greater than the batch $K_{\mathrm{d}}$. The increase in $K_{\mathrm{d}}$ app with time can be explained by diffusion mechanisms and/or time-dependent processes such as stabilization, leading to non-extractable residues. The increase in apparent sorption was greater and quicker in the Andosol than in the Vertisol. This could be related to a larger influence of pesticide diffusion processes in relation to a much greater water-retention capacity and the particularity of allophaneorganic matter associations in Andosols. Mamy and Barriuso (2007) have shown that non-extractable residues largely contribute to the increase in retention with time and non-reversible sorption phenomena. We found non-extractable residues in both soils, but larger amounts in the Andosol. For cadusafos, non-extractable residues amounted to 21 and $28 \%$ in the Vertisol and Andosol, respectively. In the case of parathion, non-extractable residues reached 34 and $44 \%$ in the Vertisol and Andosol, respectively. These levels of parathion-bound 
residues were comparable with data published in temperate soils (Katan et al., 1976; Saffih-Hdaddi et al., 2003).

Sorption coefficients such as $K_{\mathrm{d}}$ or $K_{\mathrm{fa}}$ are usually used in pesticide fate models to predict the fraction of pesticides which can be found in solution (Calvet et al., 2005). The assumptions which are commonly made are the following: the linearity of sorption isotherms $\left(\mathrm{n}_{\mathrm{a}}=1\right)$, the complete reversibility of sorption and desorption processes $(\mathrm{H}=1)$ and the non-variation in time of the sorption coefficients. In the present case, rapid sorption kinetics and the linear shapes of sorption isotherms of both insecticides allowed us to calculate $K_{\mathrm{d}}$. However, sorption of both insecticides was not reversible or time-dependent. Despite the evidence of non-reversible sorption, we used a simplistic calculation to take into account the increase in sorption with time in the estimation of the available insecticide concentration, i.e. in the soil solution. This calculation was done at the soil moisture content at $100 \%$ of the field capacity, estimated at $\mathrm{pF}=2.8$. The gravimetric water contents were 30.7 and $44.6 \%$, respectively, for Vertisol 2 and Andosol. The fraction of insecticides in the soil solution $f(t)$ at time $t$ was calculated as follows (Calvet et al., 2005):

$$
f(t)=1 /\left(1+\mathrm{m} K_{\mathrm{d} \text { app }}(t) / V\right)
$$

where $m$ is the mass of dry soil $(\mathrm{kg}), V$ the volume (L) of the soil solution at the considered soil moisture and $K_{\mathrm{d}}$ app is the apparent sorption coefficient at time $(t)$. We calculated concentrations in solution using $f(t)$ and considering the insecticide doses used in the incubation: $1 \mathrm{mg}$ parathion $\mathrm{kg}^{-1}$ soil and $0.15 \mathrm{mg}$ cadusafos $\mathrm{kg}^{-1}$ soil. At time 0 we used $K_{\mathrm{d}}$ obtained from the adsorption isotherms for the three soils. In this case, the estimated concentration of available parathion was two times greater in Vertisol $1\left(26 \mu \mathrm{g} \mathrm{L}^{-1}\right)$ than in the Andosol $\left(13 \mu \mathrm{g} \mathrm{L}^{-1}\right)$ or Vertisol $2\left(14 \mu \mathrm{g} \mathrm{L}^{-1}\right)$. For cadusafos, applied at a lower dose than parathion, the highest concentration was predicted in Vertisol $1\left(19 \mu \mathrm{g} \mathrm{L}^{-1}\right)$ and the lowest in Vertisol $2\left(11 \mu \mathrm{g} \mathrm{L}^{-1}\right)$. Taking into account the increase in $K_{\mathrm{d} \text { app }}$ over time, the available concentration of parathion dropped to 9.9 and $5.4 \mu \mathrm{g} \mathrm{L} \mathrm{L}^{-1}$ after 4 days in the Vertisol 2 and Andosol, respectively. For cadusafos, the estimated concentrations in the soil solution decreased in a similar way to reach 7.8 in the Vertisol 2 and $5.9 \mu \mathrm{g} \mathrm{L}^{-1}$ in the Andosol after 4 days. After 11 days, values ranged between 6 and $3 \mu \mathrm{g} \mathrm{L}^{-1}$ for both insecticides, with slightly higher values in the Vertisol than in the Andosol. Considering the available data on the toxicity of both compounds (EC $5048 \mathrm{~h}$ Daphnia magna: $2.5 \mu \mathrm{g} \mathrm{L}-1$ and $1.6 \mu \mathrm{L} \mathrm{L}^{-1}$, respectively, for parathion and cadusafos. Pesticide Manual, 2003; Agritox, 2005), it can be assumed that the level of concentrations found in the soil solution will have toxic effects on soil organisms for a relatively long period (30 days) despite a decreasing availability over time. Moreover, the formation and release of metabolites such as paraoxon and pnitrophenol will increase the toxic effects on soil organisms.

\section{CONCLUSION}

Despite similar $\log K_{\text {ow }}$ values, cadusafos ( $K_{\mathrm{d}}$ values 7.6-12.7 $\mathrm{L} \mathrm{kg}^{-1}$ ) was less sorbed and exhibited a greater sorp- tion reversibility than parathion in both Andosol and Vertisol soil types. Sorption coefficients of parathion $\left(K_{\mathrm{d}}\right.$ values $38.6-74.9 \mathrm{~L} \mathrm{~kg}^{-1}$ ) were greater in the more organic soils, whereas for cadusafos other soil characteristics such as clay content and cation type had an influence on the sorption processes. In contrast with the literature data concerning nonionic compounds, the amount of soil organic matter was not the main driving factor for cadusafos sorption. This could be particular to these soils (Andosol and Vertisol) and related to the role of organomineral associations in surface horizons containing high amounts of organic carbon. Our results suggest that in these soil types, predicting sorption behavior of nonionic pesticides from the $K_{\mathrm{ow}}$ parameter is not possible. Nonreversible sorption was also greater in the more organic soils. Hysteresis was two to seven times greater for parathion than cadusafos. Time-dependent sorption was a quantitatively significant phenomenon, leading to a rapid decrease in available insecticide concentration. This decrease was rapid for both molecules and influenced by the soil type. Part of the increase in sorption was attributed to the formation of non-extractable residues, which were formed in greater amount for parathion than for cadusafos. For both molecules, the greatest amount of bound residues was found in the Andosol.

Despite time-dependent non-reversible sorption and bound residues formation, both insecticides could have persistent toxic effects in the different soils studied. This was deducted from the estimations of residual insecticide concentration in the soil solution one month after application. Degradation products were detected which are known to be more toxic than the parent insecticide. Although their proportion was less than $6 \%$ of the applied insecticides, this would contribute to an increased risk for soil organisms. Additional questions arise concerning the potential toxicity of sorbed and non-extractable residues, depending on the exposed soil organisms. With the objective of assessing the environmental risk of such compounds and their residues, further studies should be conducted to evaluate their toxicological effects on soil organisms in similar soil conditions.

Acknowledgements: This work was done during the Ph.D. thesis of Angeluz Olvera-Velona, who benefited from the French-Mexican collaboration exchange program (ECOS-Nord Action M01-A03).

\section{REFERENCES}

AFNOR (2005) Évaluation de la qualité des sols. Volume 1 : Méthodes d'analyse chimique; Volume 2 : Méthodes d'analyses physique et biologique, $946 \mathrm{p}$.

Agritox: toxicological data base on pesticides, INRA (2005) At: www.inra.fr/agritox/.

Allen-King R.M., Grathwohl P., Ball W.P. (2002) New modeling paradigms for the sorption of hydrophobic organic chemicals to heterogeneous carbonaceous matter in soils, sediments and rocks, Adv. Water Resour. 25, 985-1016.

Barriuso E., Calvet R. (1991) Soil type and herbicide adsorption, Int. J. Environ. An. Ch. 46, 117-128. 
Barriuso E., Feller C., Calvet R., Cerri C. (1992) Sorption of atrazine, terbutryn and 2, 4-D herbicides in two Brasilian oxisols, Geoderma $53,155-167$.

Barriuso E., Laird D.A., Koskinen W., Dowdy R.H. (1994) Atrazine desorption from smectites, Soil Sci. Soc. Am. J. 58, 1632-1638.

Bowman B.T., Sans W.W. (1977) Adsorption of parathion, fenitrothion, methyl parathion, aminoparathion and paraoxon by $\mathrm{Na}^{+}, \mathrm{Ca}^{+}$, and $\mathrm{Fe}^{3+}$ montmorillonite suspensions, Soil Sci. Soc. Am. Proc. 41, 514-519.

Calvet R., Barriuso E., Bedos C., Benoit P., Charnay M.P., Coquet Y. (2005) Devenir des pesticides dans les sols, Éditions France Agricole, Paris.

CICOPLAFEST (2004) Comisión Intersecretarial para el Control de Proceso y Uso de Plaguicidas, Fertilizantes y Sustancias Tóxicas. Catálogo Oficial de Plaguicidas. SAGARPA, SEDESOL, Méx, D.F. 481.

FOOTPRINT (2006) The FOOTPRINT Pesticide Properties DataBase, University of Hertfordshire as part of the EU-funded FOOTPRINT project (FP6-SSP-022704), http://www.eu-footprint.org/ppdb.html.

Führemann T.W, Lichtenstein E.P. (1978) Release of soil-bound methyl $\left[{ }^{14} \mathrm{C}\right]$ parathion residues and their uptake by earthworms and oat plants, J. Food. Agr. Chem. 26, 605-610.

Gevao B., Mordaunt C., Semple K.T., Piearce T.G., Jones K.C. (2001) Bioavailability of nonextractable (bound) pesticide residues to earthworms, Environ. Sci. Technol. 35, 501-507.

Hamaker J.W., Thompson J.M. (1972) Adsorption of organic chemicals in the soil environment, Vol. 1, in: Goring C.A.I., Hammaker J.W. (Eds.), Marcel Dekker, New York, pp. 49-143.

Hassett J.J., Banwart W.L., Griffin R.A. (1983) Correlation of compound properties with sorption characteristics of non polar compounds by soils and sediments: concepts and limitations, in: Francis C.W., Auerbach S.I. (Eds.), Environment and solid wastes, Butterworth, Boston, pp. 161-178.

INEGI (2004) Carta Edafológica y Anuario Estadístico del Estado de Morelos, Instituto Nacional de Estadística Geografía e Informática. Edición 2004, Méx, D.F.

Kaiser K., Guggenberger G. (2003) Mineral surfaces and soil organic matter, Eur. J. Soil Sci. 54, 219-236.

Katan J., Fuhremann T.W., Lichtenstein E.P. (1976) Binding of ${ }^{14} \mathrm{C}$ parathion in soil: A reassessment of pesticide persistence, Science 193, 891-894.

Koskinen W.C., Harper S.S. (1990) The retention process: mechanisms, in: Cheng H.H. (Ed.), Pesticides in the Soil Environment: Processes, Impacts and Modelling, SSA Book Series 2, SSSA, Madison, WI, pp. 51-77.

Laabs V., Amelung W. (2005) Sorption and aging of corn and soybean pesticides in tropical soils of Brazil, J. Agr. Food Chem. 53, 71847192.

Leenheer J.A., Ahlrichs J.L. (1971) A kinetic and equilibrium study of the adsorption of carbaryl and parathion upon soil organic matter surfaces, Soil Sci. Soc. Am. Proc. 35, 700-705.

Mamy L., Barriuso E. (2007) Desorption and time-dependent sorption of herbicides in soils, Eur. J. Soil Sci. 58, 174-187.
Oliver D.P., Kookana R.S., Quintana B. (2005) Sorption of pesticides in tropical and temperate soils from Autralia and Philippines, J. Agr. Food Chem. 53, 6420-6425.

Pignatello J.J. (2000) The measurement and interpretation of sorption and desorption rates for organic compounds in soil media, Adv. Agron. 69, 1-73.

Pehkonen S.O., Zhang Q. (2002) The degradation of organophosphorus pesticides in natural waters: a critical review, Crit. Rev. Env. Sci. Tec. 32, 17-72.

Pesticide Manual (2003) Incorporating the Agrochemicals Handbook, 13th ed., n. Crop Protection Publication, British Crop Protection Council, The Royal Society of Chemisty, London, 1344 p.

Racket K.D. (2003) What do we know about the fate of pesticides in tropical ecosystems? in: Coast J.R, Yamamoto H. (Eds.), Environmental fate and effects of pesticides, American Chemical Society, Washington, DC, pp. 96-123.

Saffih-Hdaddi K., Bruckler L., Barriuso E. (2003) Modeling of sorption and biodegradation of parathion and its metabolite paraoxon in soil, J. Environ. Qual. 32, 2207-2215.

Saltzmann S., Kliger L., Yaron B. (1972) Adsorption-desorption of parathion as affected by soil organic matter, J. Agr. Food Chem. $16,21-23$.

Sanchez Martin M.J., Sanchez Camazano M. (1991) Relationship between the structure of organophosphorus pesticides and adsorption by soil components, Soil Sci. 152, 283-288.

Wauchope R.D., Yeh S., Linders J.B.H.J., Kloskowski R., Tanaka K., Rubin B., Katayama A., Kordel W., Gerstl Z., Lane M., Unsworth J.B. (2002) Pesticide soil sorption parameters: theory, measurement, uses, limitations and reliability, Pest Manag. Sci. 58, 419445 .

Weber J.B., Best J.A., Gonese J.U. (1993) Bioavailability and bioactivity of sorbed organic chemicals, in: Linn D.M. (Ed.), Sorption and degradation of pesticides and organic chemicals in soil, SSSA special publication No. 32, Madison, Wisconsin, pp. 153-193.

Weber J.B., Wilkerson G.G., Reinhardt F.C. (2004) Calculating pesticides sorption coefficients $(\mathrm{Kd})$ using selected soil properties, Chemosphere 55, 157-166.

Worrall F., Parker A., Rae J.E., Johnson A.C. (1996) Equilibrium adsorption of isoproturon on soil and pure clays, Eur. J. Soil Sci. 47, 265272.

WRB (1998) World Reference base for Soil Resources. FAO, ISRIC and ISSS $^{(}$, Food and Agriculture Organization of the United Nations.

Yaron B., Saltzmann S. (1978) Soil-parathion surface interactions, Res. Rev. 69, 1-34.

Zheng S.Q., Cooper J.F. (1996) Adsorption, desorption, and degradation of three pesticides in different soils, Arch. Environ. Con. Tox. 30, $15-20$.

Zheng S.Q., Cooper J.F., Palcy L., Coste C.M., Marnotte P. (1994) Mobility and dissipation of cadusafos in banana fields in Martinique, Sci. Total Environ. 156, 1-9. 